\section{PSYCHO-STATS 80: A basic statistical package for the TRS- 80}

\author{
DAVID E. ANDERSON \\ Allegheny College, Meadville, Pennsylvania 16335
}

Gilbert's (1979) PSYCHOSTATS computer programs of statistical procedures were designed for an $8 \mathrm{~K}$ minicomputer. PSYCHO-STATS 80 represents a translation of most of Gilbert's programs to TRS-80 BASIC. In addition, several new programs have been added. The programs translated from Gilbert's include (1) Student's $t$ tests: single, independent, and dependent samples; (2) one-way ANOVAs: simple and with repeated measures; (3) two-way ANOVAs: simple, with repeated measures on one factor and with repeated measures on two factors; (4) three-way ANOVAs: simple and with one or two repeated measures; (5) multiple and pairwise comparisons: one-, two-, and three-way; (6) simple main effects: two- and three-way; (7) Latin squares: simple and with repeated measures on one or two factors; (8) analyses of covariance: one-way, one-way with repeated measures, and two-way; (9) correlation with missing values as well as simple linear regression; (10) nonparametric: Mann-Whitney, Wilcoxon, Spearman, Kendall, Kruskal-Wallis, Friedman, and Cochran; and (11) chi square: single and double classification. Although the logic of the programs is essentially the same as in PSYCHOSTATS, overlays have been eliminated, comments and prompts have been expanded greatly, and, at least for some programs, the option of input from data stored on a TRS- 80 diskette file has been provided.

Three new programs have been added to the package. The first provides descriptive statistics (mean, standard deviation, variance, etc.) for a single variable. A correlation program has been added that prints a scatter diagram on a line printer. The third new program builds a disk file of raw data that can then be read by one or more of the data analysis programs.

As with the original package, the programs are all interactive and provide for the recovery of errors in raw data input.

Language and Computer. The programs are written in TRS-80 BASIC for a 32K Model I machine. A printer and one or two disk drives are required.

Availability. Copies of the program are available on three 51/4-in. diskettes for $\$ 20$ (to cover costs of the diskettes) from the author. Make checks payable to the Department of Psychology, Allegheny College.

\section{REFERENCE}

GILBERT, L. H. PSYCHOSTATS: Basic programs for data analysis in psychology. Behavior Research Methods \& Instrumentation, $1979,11,464$.

(Accepted for publication October 20, 1980.) 